\title{
BMJ Open Can we prevent poststroke cognitive impairment? An umbrella review of risk factors and treatments
}

\author{
Majed Obaid (D) , ${ }^{1,2}$ Abdel Douiri, ${ }^{1,3}$ Clare Flach, ${ }^{1}$ Vibhore Prasad, ${ }^{1}$ \\ lain Marshall (1) ${ }^{1,3}$
}

To cite: Obaid M, Douiri A, Flach C, et al. Can we prevent poststroke cognitive impairment? An umbrella review of risk factors and treatments. BMJ Open 2020;10:e037982. doi:10.1136/ bmjopen-2020-037982

- Prepublication history for this paper is available online. To view these files, please visit the journal online (http://dx.doi org/10.1136/bmjopen-2020037982).

Received 24 February 2020 Revised 15 July 2020 Accepted 27 July 2020

Check for updates

(c) Author(s) (or their employer(s)) 2020. Re-use permitted under CC BY-NC. No commercial re-use. See rights and permissions. Published by BMJ.

${ }^{1}$ Primary Care and Public Health Sciences, Division of Health and Social Care Research, King's College London, London, UK ${ }^{2}$ Department of Community Medicine and Medical Care for Pilgrims, Faculty of Medicine, Umm Al-Qura University, Makkah, Saudi Arabia ${ }^{3}$ National Institute for Health Research Comprehensive Biomedical Research Centre, Guy's and St. Thomas' NHS Foundation Trust, London, UK

Correspondence to

Dr Majed Obaid

majed.obaid@kcl.ac.uk

\section{ABSTRACT}

Objectives Cognitive impairment poststroke is progressive. We aimed to synthesise the existing evidence evaluating risk factors and the effects of treatments to prevent/improve cognitive function in patients who had a stroke with cognitive impairment. Design Umbrella review.

Data source Medline, PsycINFO, EMBASE, Cochrane and PROSPERO were searched from inception until 11 June 2019.

Eligibility criteria Published systematic review (SR) that incorporated randomised controlled trials to investigate an intervention to improve poststroke cognitive impairment, or SR of longitudinal observational studies that evaluated the risk factors of this condition. No restrictions were applied.

Data extraction and synthesis From each eligible study, details were recorded by one reviewer in a validated form. Grading of Recommendations, Assessment, Development and Evaluations criteria were used to assess our certainty level of each outcome, and A Measurement Tool to Assess Systematic Reviews 2 to assess quality.

Results Altogether, 3464 abstracts were retrieved, 135 full texts were evaluated and 22 SRs were included in the final analysis. From four SRs of observational studies, we found 19 significant associations with postulated risk factors, and those which we determined to be confident about were: atrial fibrillation (3 SRs, 25 original studies); relative risk 3.01 (1.96-4.61), ORs 2.4 (1.7-3.5) and 2.0 (1.4-2.8), leukoaraiosis, multiple and recurrent strokes, ORs 2.5 (1.9-3.4), 2.5 (1.9-3.1) and 2.3 (1.5-3.5), respectively. From 18 SRs of interventional trials, we found that interventions including physical activity or cognitive rehabilitation were enhancing cognitive function, while the certainty of the other interventions was rated low, due to limited methodological quality.

Conclusions This review represents common risk factors related to poststroke cognitive impairment, in particular atrial fibrillation, and points to different interventions that warrant attention in the development of treatment strategies. Physical activity and cognitive rehabilitation interventions showed evidence of enhancing cognitive function; however, we could not recommend a change in practice yet, due to lack of strong evidence.

PROSPERO registration number CRD42018096667.

\section{Strengths and limitations of this study}

- This study provides an overview on a broad topic by using a systematic approach.

- The quality of the evidence was assessed at different levels, including A Measurement Tool to Assess Systematic Reviews and Grading of Recommendations, Assessment, Development and Evaluations criteria.

- This study included only systematic reviews of randomised controlled trials to assess the effectiveness of an intervention.

- Even though we used different levels of quality assessments, conducting an umbrella review might carry forward the methodological limitations of previous reviews.

\section{INTRODUCTION}

Stroke is the second leading cause of death after ischaemic heart disease and a major cause of long-term disability worldwide. ${ }^{1}$ Recovery from stroke poses physical and psychological challenges, with significant consequences for patients and families, informal caregivers and stroke services. ${ }^{2}$ There is a growing literature on the importance of poststroke cognitive impairment as a determinant of return to work for stroke survivors. ${ }^{3}$ Cognitive impairment after stroke affects over one-third of patients, and may result in poor clinical outcomes, ${ }^{4}$ reduction in quality of life and extended hospital stays. ${ }^{56}$

A James Lind Alliance priority setting exercise found that finding ways to prevent poststroke cognitive impairment was the number one research priority for patients, carers and clinicians. ${ }^{7}$ Many systematic reviews (SR) have been published investigating the effectiveness of a single intervention, ${ }^{89}$ or evaluating risk factors associated with cognitive decline. ${ }^{1011}$

To provide an overview of this field of research as a whole and investigating our research question 'Can we prevent post-stroke cognitive impairment?', we aim to synthesise 
the results of these SRs using a method known as an 'umbrella' review, or SR of SRs . ${ }^{12}$ This method entails systematically identifying all SRs pertinent to a research field, and synthesising their results, taking into account an assessment of quality and bias. Umbrella reviews can help clinicians and policymakers gain a clear understanding of a diverse field, are useful for patients seeking information about available treatment choices and their effectiveness. Rather than directly summarising these reviews, we aim to appraise the quality of both the included reviews and the studies included in those reviews, and present results using the Grading of Recommendations, Assessment, Development and Evaluations (GRADE) framework, to provide information about how confident we are in our findings.

\section{METHODS}

This SR was conducted in accordance with the recommendations of the Cochrane Collaboration and the Preferred Reporting Items for Systematic Reviews and Meta-Analyses (PRISMA) guidelines. ${ }^{13}$ The study protocol was prespecified and registered in advance of the literature search in the International Prospective Register of Systematic Reviews (PROSPERO).

\section{Search strategy and selection criteria}

This umbrella review, which is a method used to collect SRs and meta-analyses to answer a specific question, ${ }^{12}{ }^{14}$ was conducted. We systematically searched Medline (Ovid), PsycINFO (Ovid), EMBASE (Ovid), the Cochrane Library, PROSPERO and Scopus from inception until 11 June 2019. Grey literature was also searched using the OpenGrey website. ${ }^{15}$ Search terms from a previous Cochrane SR were adapted and used as the basis for our search strategy. ${ }^{16}$ Study design search filters were taken from the Scottish Intercollegiate Guidelines Network to identify SRs. Specialist librarians were consulted regarding the search terms before and after a pilot search stage. The search terms for the three databases (Medline, PsycINFO, EMBASE) are provided in online supplementary file 1.

One member of the research team (MO) performed the initial search and removed titles and abstracts that were clearly outside of the scope of the review. All the remaining abstracts were screened by two independent researchers; this screening was done by MO, and IJM or $\mathrm{AD}$. In case of disagreement, a third reviewer was consulted (VP). Studies were included if they were: (1) peer-reviewed SRs with or without meta-analysis that identified risk factors or interventions for poststroke cognitive impairment; (2) included adult participants aged 18 years and older, with a history of stroke based on the WHO definition ${ }^{17}$ (patients with a history of traumatic brain injury, transient ischaemic attack and other neurological deficits were excluded); (3) considered randomised controlled trials (RCTs) for testing the effectiveness of interventions, and longitudinal studies with a minimum of 3 months of follow-up to explore the association between risk factors and cognitive decline. We included trials that compared a treatment group that received one of the various types of interventions (pharmacological or non-pharmacological) to improve/prevent cognitive impairment after stroke, and a control group that received either a different form of or no intervention. Intervention after stroke was considered where cognition was either a primary or secondary outcome. No restrictions to language were applied.

The definition of poststroke cognitive impairment varies in the literature. ${ }^{18}$ In this review we considered generally the criteria reported by Gorelick et al. ${ }^{19}$ The criteria include that vascular cognitive impairment (VCI) incorporates a range of cognitive deficits, from relatively mild cognitive impairment of vascular origin to vascular dementia, the most severe form of VCI. VCI is a syndrome affecting at least one cognitive domain with evidence of clinical stroke. However, studies that were inconsistent with the Gorelick criteria might be considered if the inclusion criteria we described in the protocol will be fulfilled.

Furthermore, cognition typically includes various domains such as attention, memory and executive functioning. ${ }^{18}$ However, some authors include problems with visuospatial perception and apraxia as cognitive impairments. ${ }^{20}$ Much research in the field separates these latter pathology domains from cognitive impairment. For this review, we follow specifically the definition of The National Stroke Foundation of Australia's Clinical Guidelines for Stroke Rehabilitation and Recovery, which specifies cognitive impairment to include the following domains: attention, orientation, memory and executive functions. ${ }^{21}$

\section{Outcomes}

Our primary outcomes were change in cognitive function after delivering an intervention. Test of cognitive function was not restricted to a specific tool. It could include global cognitive function (eg, Mini-Mental State Examination (MMSE)), individual tests (eg, TrailMaking Test), neuropsychological test battery (a combination of individual cognitive tests) or specific domains assessment of executive function, attention, memory or perception. Second, we evaluated risk factors associated with increasing or decreasing the risk of cognitive impairment after stroke. Adverse effects for interventions were reported as a secondary outcome.

\section{Data extraction and synthesis}

From each eligible study, the following details were recorded by MO in a form that was validated and approved by all the team members: first author, title, publication year, last search year, participant characteristics, number, setting, country, sex, description of intervention; type, duration, frequency and time since stroke onset; study design, inclusion/exclusion criteria, measurement tools, primary outcomes, other outcomes, statistical tests, adverse events and quality of the individual studies.

For each SR of intervention, absolute effect sizes (mean difference or standardised mean difference (SMD) 
between two groups) with $95 \%$ CIs were reported. For studies evaluating risk factors, ORs or relative risks (RRs) were extracted with $95 \%$ CIs to estimate association. Between-study heterogeneity by $\mathrm{I}^{2}$ metric was extracted, with values under $40 \%$ indicating that heterogeneity may not be significant. However, higher levels indicate likely heterogeneity, with levels above $50 \%$ representing substantial heterogeneity. ${ }^{22}$

To ease interpretation of standardised results, we translated the effects of interventions into their equivalents in percentages using the MMSE and the Montreal Cognitive Assessment (MoCA) as a reference. The MMSE and MoCA use a maximum score of $30 .^{23}$

We also classified each outcome using criteria from the GRADE framework to present the certainty of findings, which is defined as a systematic approach to rating the certainty of evidence in SRs and other syntheses of evidence. ${ }^{24}$ GRADE was conducted on the basis of the outcomes reported in a review article and carried out by one reviewer (MO) and revised independently by two reviewers (AD and IJM). GRADE has four levels of evidence certainty: high, moderate, low and critically low. Evidence from RCTs starts at high quality, while evidence that includes observational data starts at low quality due to residual confounding. The certainty in the evidence is increased or decreased for several reasons (eg, imprecision, indirectness, inconsistency, risk of bias, large magnitude of effect and all plausible confounders). High certainty indicates that we have a strong confidence that the true effect is similar to the estimated effect. Whereas very low certainty indicates that the true effect is probably markedly different from the estimated effect, moderate and low certainty set in between these statements.

\section{Quality assessment}

We examined the general methodological quality of SRs using A Measurement Tool to Assess Systematic Reviews $2,{ }^{25}$ which includes 16 reliable and valid items. Based on the tool, the overall rating of the general methodological quality would be reported as high, moderate, low and critically low. Subsequently, we also considered the quality assessment from the SRs regarding the quality of the primary studies. The assessment was performed by $\mathrm{MO}$ and checked independently by IJM or AD.

\section{Patient and public involvement}

No patients involved.

\section{RESULTS}

The initial search provided a total of 3464 relevant titles and abstract, which was further refined to the retrieval of 135 full-text articles. Of these, 22 SRs were eligible for inclusion in the final synthesis. The study selection process, including reasons for exclusion at the full-text level, is summarised in a PRISMA study flow diagram (figure 1). The characteristics of the included reviews are presented in tables 1 and 2. All studies included 30715 participants who had a history of stroke, except one SR of a physical activity including altogether 482 participants, of which 87 had not had a stroke, ${ }^{26}$ for which the data were not reported separately. This umbrella review included 18

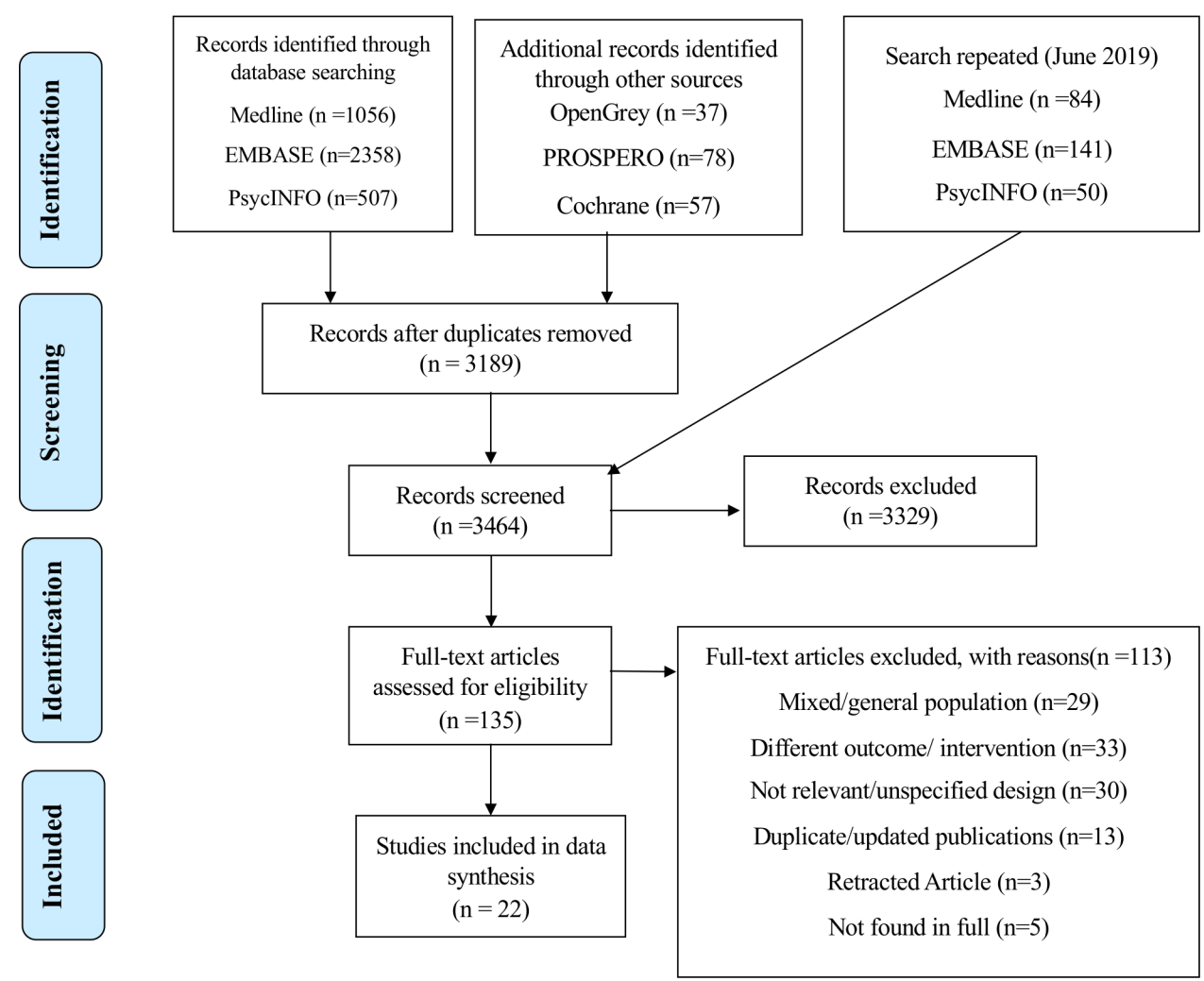

Figure 1 Preferred Reporting Items for Systematic Reviews and Meta-Analyses (PRISMA) flow chart for study selection. 
Table 1 Participant characteristics in systematic reviews that evaluated risk factors

\begin{tabular}{|c|c|c|c|c|c|c|}
\hline First author & Study design & $\begin{array}{l}\text { Publication } \\
\text { year }\end{array}$ & $\begin{array}{l}\text { Primary } \\
\text { studies }\end{array}$ & $\mathbf{n}$ & Age (years) & Risk factors investigated \\
\hline Kalantarian ${ }^{10}$ & $\begin{array}{l}\text { SR of longitudinal } \\
\text { observational studies }\end{array}$ & 2013 & $5^{\star}$ & 1394 & Mean: 71 & Atrial fibrillation \\
\hline Kwok $^{41}$ & $\begin{array}{l}\text { SR of longitudinal } \\
\text { observational studies }\end{array}$ & 2011 & $7^{*}$ & 2425 & Mean: 68 & Atrial fibrillation \\
\hline Tang $^{11}$ & $\begin{array}{l}\text { SR of longitudinal } \\
\text { observational studies }\end{array}$ & 2018 & 14 & 11400 & NA & $\begin{array}{l}\text { Increased age, female sex, left } \\
\text { lesion location and black ethnicity }\end{array}$ \\
\hline Pendlebury ${ }^{42}$ & $\begin{array}{l}\text { SR of longitudinal } \\
\text { observational studies }\end{array}$ & 2009 & 30 & 7511 & NA & $\begin{array}{l}\text { Atrial fibrillation, female sex, } \\
\text { white, low education, diabetes, } \\
\text { ischaemic heart disease, previous } \\
\text { TIA, hypertension, smoking, } \\
\text { moderate alcohol consumption, } \\
\text { haemorrhagic stroke, dysphagia, } \\
\text { left hemisphere lesion, brainstem, } \\
\text { lacunar, previous, recurrent, silent } \\
\text { and multiple stroke, hypoxic } \\
\text { ischaemic episode, incontinence, } \\
\text { acute confusion, early seizures, } \\
\text { abnormal electroencephalogram, } \\
\text { leukoaraiosis, atrophy and MTLA }\end{array}$ \\
\hline
\end{tabular}

*Subset.

MTLA, medial temporal lobe atrophy ; NA, not available ; SR, systematic review; TIA, transient ischaemic attack.

SRs of RCTs and four SRs of observational longitudinal studies, to assess interventions and risk factors, respectively. However, one review of physical activity interventions ${ }^{27}$ included mixed study designs, six RCTs and four non-RCTs which were not reported separately.

\section{Risk factors for poststroke cognitive impairment}

Reviews of risk factors which included four SRs (comprising 56 observational studies and 22730 participants) addressing questions regarding risk factors for poststroke cognitive impairment are shown in table 3 . Significant predictors for poststroke cognitive impairment included vascular risk factors: atrial fibrillation (AF; 3 SRs, 25 primary studies and 7466 participants, RR 3.01 (1.964.61), ORs $2.4(1.7-3.5)$ and 2.0 (1.4-2.8)) and diabetes (OR 1.4 (1.2-1.7)); demographic factors: female sex (OR 1.3 (1.1-1.6)), white ethnicity (OR $0.6(0.4-0.8)$ ) and low education (OR 2.5 (1.8-3.4)); stroke-related factors: haemorrhagic stroke (OR 1.4 (1.1-1.9)), dysphasia (OR 3.6 (2.1-6.1)), left hemispheric stroke (OR 1.4 (1.1$1.7)$ ), previous stroke (OR $1.9(1.5-2.3)$ ), multiple areas of stroke (OR 2.5 (1.9-3.1)) and recurrent stroke (OR 2.3 (1.5-3.5)); stroke complication factors: hypoxic ischaemic episode (OR 2.4 (1.4-4.2)), urine incontinence (OR 6.4 (4.5-9.2)), acute confusion (OR 2.8 (1.5-5.3)), early seizures (OR 5.4 (2.4-12.1)) and abnormal electroencephalogram (OR 2.7 (1.4-4.9)); and three changes in brain imaging: leukoaraiosis (OR 2.5 (1.9-3.4)), atrophy (OR 2.6 (1.1-6.3)) and medial temporal lobe atrophy (OR $2.7(1.8-4.2)$ ). We also observed that inadequate adjustment for confounders across studies that investigated risk factors was performed.
GRADE assessment was done to show our level of confidence of each estimate. Although observational studies in GRADE initially attract a 'low' certainty rating, in some cases large effect sizes allowed an increase in certainty. A substantial association was observed across four outcomes as follows: $\mathrm{AF}$, leukoaraiosis, recurrent and multiple areas of strokes. Details of GRADE assessment of each outcome are presented in table 3 .

\section{Interventions for poststroke cognitive impairment}

Reviews of interventions that included 18 SRs (129 RCTs; 7985 participants) addressing questions around treatments to improve cognition are shown in table 4 . The interventions which led to improved cognition function (percentage improvement in cognitive scores) compared with control included non-pharmacological: acupuncture $(10.4 \%(6.8-14))$, transcranial magnetic stimulation (13\% (8-18)) and Chinese herbal medicine (9\% (6-11)); pharmacological: antihypertensive drug withdrawal (3\% (1-5)) but associated with serious adverse effect (a sudden rise in blood pressure), and three physical activities (1\% (0.2-3), 2\% (1-3) and 4\% (3-5)). Interventions that investigated dopamine agonists ${ }^{28}$ and visual mental practice $^{29}$ had no available data and were excluded from data synthesis.

Inconsistent results were observed across physical activity interventions, which were the most common type of intervention identified ( 5 SRs and 39 RCTs). Of these, three recently published reviews $(n=3),{ }^{26} 2730$ with bigger sample size than the other non-significant studies, indicated some benefits in cognitive function, although very 
Table 2 Participant characteristics in systematic reviews that investigated interventions

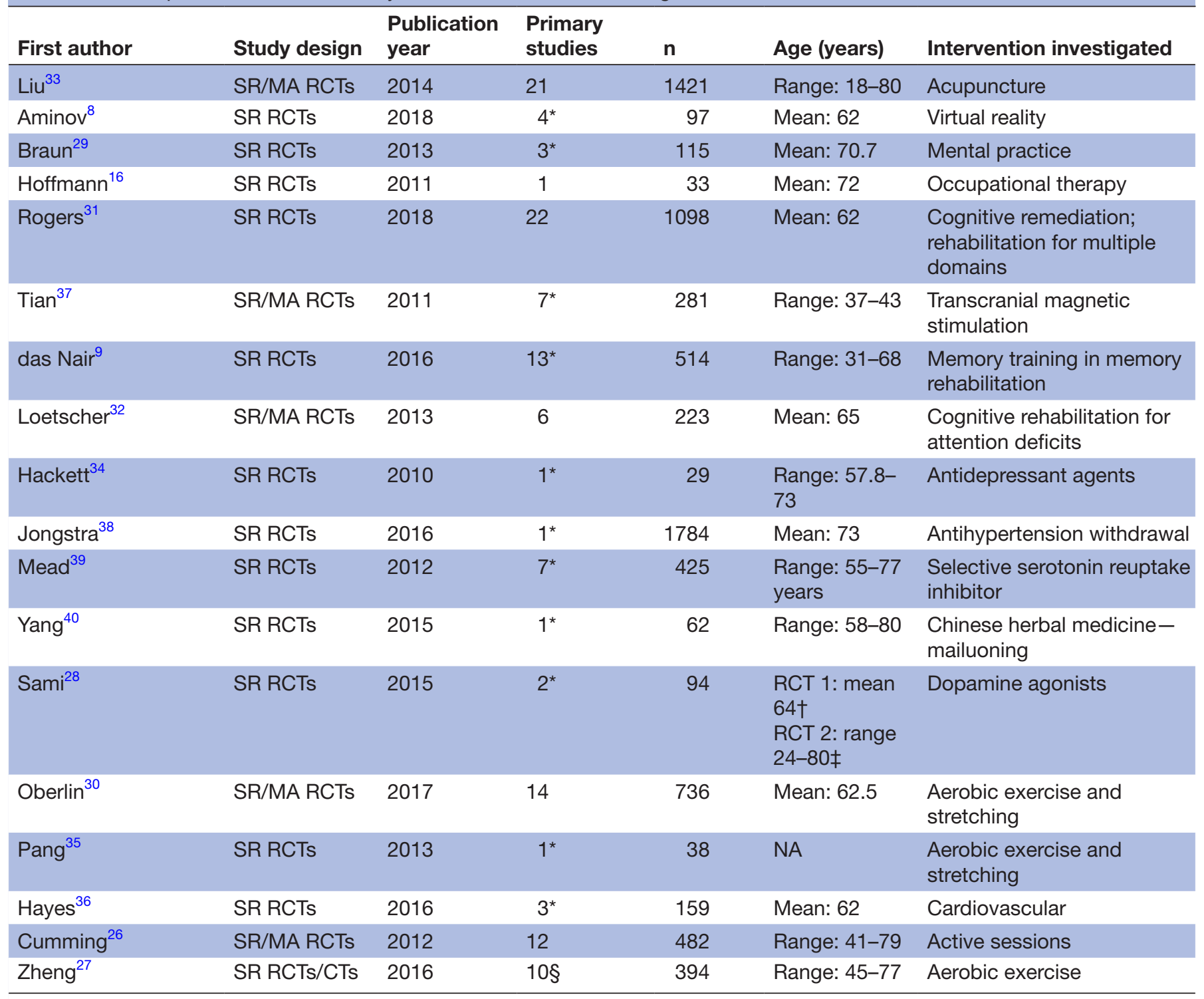

*Subset.

†Delbari et al. ${ }^{52}$

‡Gorgoraptis et al. ${ }^{53}$

$\S S i x$ RCTs/four CTs.

CT, controlled trial; ; MA, meta-analysis; NA, not available; RCT, randomised controlled trial; SR, systematic review.

small (percentage improvement in cognitive scores: $1 \%$ $(0.2-3), 2 \%(1-3)$ and $4 \%(3-5))$.

Cognitive rehabilitation interventions were the second most common type of intervention identified (3 SRs and 41 RCTs). Of these, only one recently published SR (22 RCTs; 1098 participants) investigated the effect of cognitive rehabilitation on multiple cognitive domains, ${ }^{31}$ which showed a small positive effect on cognitive function after stroke $(\mathrm{SMD}=0.48(0.35-0.60))$; whereas the other two were focusing on only one cognitive domain: attention ${ }^{32}$ and memory, ${ }^{9}$ respectively (table 4 ).

Using the GRADE criteria, we judged the certainty of the supporting evidence of treatments as moderate $(\mathrm{n}=2),{ }^{3031}$ low $(\mathrm{n}=6)^{832-36}$ and very low $(\mathrm{n}=8) .{ }^{916} 262737-40$
Methodological limitations were common across studies that reduce our certainty level for each intervention; for example, loss of follow-up, ${ }^{33}$ performance bias, ${ }^{9} 1626273740$ failure in randomisation ${ }^{2731}$ and missing data. ${ }^{35740}$ Details on limitations for each outcome, size of effect, heterogeneity, time of follow-up, time and tool of cognitive assessment are presented in table 4 .

\section{Secondary outcomes}

Only few adverse effects were observed with interventional studies as follows: higher blood pressure in the intervention group, ${ }^{37}$ confusion and tiredness, ${ }^{29}$ falls during sessions ${ }^{35}$ and recurrent stroke in few cases. ${ }^{39}$ 
Table 3 Summary of risk factors using GRADE

\begin{tabular}{|c|c|c|c|c|c|}
\hline & Risk factor & $\begin{array}{l}\text { n (primary } \\
\text { studies) Type } \\
\text { of primary } \\
\text { studies }\end{array}$ & GRADE & $\begin{array}{l}\text { Absolute effect } \\
\text { OR (95\% Cl) }\end{array}$ & $I^{2}(\%)$ \\
\hline \multirow[t]{9}{*}{ Vascular } & \multirow[t]{3}{*}{ Atrial fibrillation ${ }^{104142}$} & $\begin{array}{l}1394(5 \ddagger) \\
L(+2)\end{array}$ & $\begin{array}{l}\oplus \oplus \oplus \bigcirc \text { Moderate } \\
\text { Due to the magnitude of } \\
\text { effect }\end{array}$ & $3.01(1.96 \text { to } 4.61)^{*} \dagger$ & 0 \\
\hline & & $\begin{array}{l}2425(7 \ddagger) \\
L(+2)\end{array}$ & $\begin{array}{l}\oplus \oplus \oplus \bigcirc \text { Moderate } \\
\text { Due to magnitude of effect }\end{array}$ & $2.4(1.7 \text { to } 3.5)^{\star}$ & 10 \\
\hline & & $\begin{array}{l}3647(13) \\
L(+2)\end{array}$ & $\begin{array}{l}\oplus \oplus \bigcirc \bigcirc \text { Low } \\
\text { Due to magnitude of effect } \\
\text { and inconsistency }\end{array}$ & $2.0(1.4 \text { to } 2.8)^{\star}$ & 55 \\
\hline & Diabetes $^{42}$ & $\begin{array}{l}4809(19) \\
L(+2)\end{array}$ & $\oplus \oplus \bigcirc \bigcirc$ Low & $1.4(1.2 \text { to } 1.7)^{*}$ & 10 \\
\hline & Hypertension $^{42}$ & $\begin{array}{l}4800(19) \\
L(+2)\end{array}$ & $\begin{array}{l}\oplus \bigcirc \bigcirc \bigcirc \text { Very low } \\
\text { Due to imprecision }\end{array}$ & 1.1 (0.9 to 1.3$)$ & 0 \\
\hline & Smoking ${ }^{42}$ & $\begin{array}{l}4163(16) \\
L(+2)\end{array}$ & $\begin{array}{l}0000 \text { Critically low } \\
\text { Due to imprecision and } \\
\text { inconsistency }\end{array}$ & 1.0 (0.8 to 1.2$)$ & 54 \\
\hline & $\begin{array}{l}\text { Moderate alcohol } \\
\text { consumption }^{42}\end{array}$ & $\begin{array}{l}2822(9) \\
L(+2)\end{array}$ & $\begin{array}{l}\oplus \bigcirc \bigcirc \bigcirc \text { Very low } \\
\text { Due to imprecision }\end{array}$ & 0.8 (0.6 to 1.0$)$ & 45 \\
\hline & $\begin{array}{l}\text { Ischaemic heart } \\
\text { disease }^{42}\end{array}$ & $\begin{array}{l}3739(14) \\
L(+2)\end{array}$ & $\begin{array}{l}\oplus \bigcirc \bigcirc \bigcirc \text { Very low } \\
\text { Due to imprecision }\end{array}$ & 1.0 (0.8 to 1.3$)$ & 46 \\
\hline & Previous TIA ${ }^{42}$ & $\begin{array}{l}3411(11) \\
\mathrm{L}(+2)\end{array}$ & $\begin{array}{l}\oplus \bigcirc \bigcirc \bigcirc \text { Very low } \\
\text { Due to imprecision }\end{array}$ & $1.0(0.8$ to 1$)$ & 27 \\
\hline \multirow[t]{3}{*}{ Demographic } & Female sex ${ }^{42}$ & $\begin{array}{l}5707(24) \\
L(+2)\end{array}$ & $\oplus \oplus \bigcirc \bigcirc$ Low & $1.3(1.1 \text { to } 1.6)^{*}$ & 49 \\
\hline & White $^{42}$ & $\begin{array}{l}1245(3) \\
L(+2)\end{array}$ & $\oplus \oplus \bigcirc \bigcirc$ Low & $0.6(0.4 \text { to } 0.8)^{*}$ & 1 \\
\hline & Low education ${ }^{42}$ & $\begin{array}{l}2787(11) \\
L(+2)\end{array}$ & $\oplus \oplus \bigcirc \bigcirc$ Low & $2.5(1.8 \text { to } 3.4)^{*}$ & 56 \\
\hline \multirow[t]{9}{*}{ Stroke related } & Haemorrhagic stroke $e^{42}$ & $\begin{array}{l}1252(9) \\
L(+2)\end{array}$ & $\oplus \oplus \bigcirc \bigcirc$ Low & $1.4(1.1 \text { to } 1.9)^{*}$ & 2 \\
\hline & Dysphasia $^{42}$ & $\begin{array}{l}2223(7) \\
L(+2)\end{array}$ & $\begin{array}{l}\oplus \oplus \bigcirc \bigcirc \text { Low } \\
\text { Due to inconsistency and } \\
\text { magnitude of effect }\end{array}$ & $3.6(2.1 \text { to } 6.1)^{\star}$ & 71 \\
\hline & $\begin{array}{l}\text { Left hemisphere } \\
\text { stroke }^{42}\end{array}$ & $\begin{array}{l}4599(17) \\
L(+2)\end{array}$ & $\oplus \oplus \bigcirc \bigcirc$ Low & $1.4(1.1 \text { to } 1.7)^{\star}$ & 48 \\
\hline & Brainstem stroke $e^{42}$ & $\begin{array}{l}3042(9) \\
L(+2)\end{array}$ & $\begin{array}{l}000 \bigcirc \text { Critically low } \\
\text { Due to imprecision and } \\
\text { inconsistency }\end{array}$ & 0.7 (0.4 to 1.2$)$ & 75 \\
\hline & Lacunar stroke $e^{42}$ & $\begin{array}{l}2895(10) \\
L(+2)\end{array}$ & $\begin{array}{l}\oplus \bigcirc \bigcirc \bigcirc \text { Very low } \\
\text { Due to imprecision }\end{array}$ & 0.8 (0.7 to 1.0$)$ & 0 \\
\hline & Previous stroke $e^{42}$ & $\begin{array}{l}2766(10) \\
L(+2)\end{array}$ & $\oplus \oplus \bigcirc \bigcirc$ Low & $1.9(1.5 \text { to } 2.3)^{\star}$ & 0 \\
\hline & Multiple strokes ${ }^{42}$ & $\begin{array}{l}2730(9) \\
L(+2)\end{array}$ & $\begin{array}{l}\oplus \oplus \oplus \bigcirc \text { Moderate } \\
\text { Due to magnitude of effect }\end{array}$ & $2.5(1.9 \text { to } 3.1)^{\star}$ & 16 \\
\hline & Recurrent stroke $e^{42}$ & $\begin{array}{l}947(4) \\
L(+2)\end{array}$ & $\begin{array}{l}\oplus \oplus \oplus \bigcirc \text { Moderate } \\
\text { Due to magnitude of effect }\end{array}$ & $2.3(1.5 \text { to } 3.5)^{\star}$ & 14 \\
\hline & Silent strokes ${ }^{42}$ & $\begin{array}{l}775(5) \\
L(+2)\end{array}$ & $\begin{array}{l}0000 \text { Critically low } \\
\text { Due to imprecision and } \\
\text { inconsistency }\end{array}$ & 1.8 (0.9 to 3.5$)$ & 63 \\
\hline
\end{tabular}

Continued 


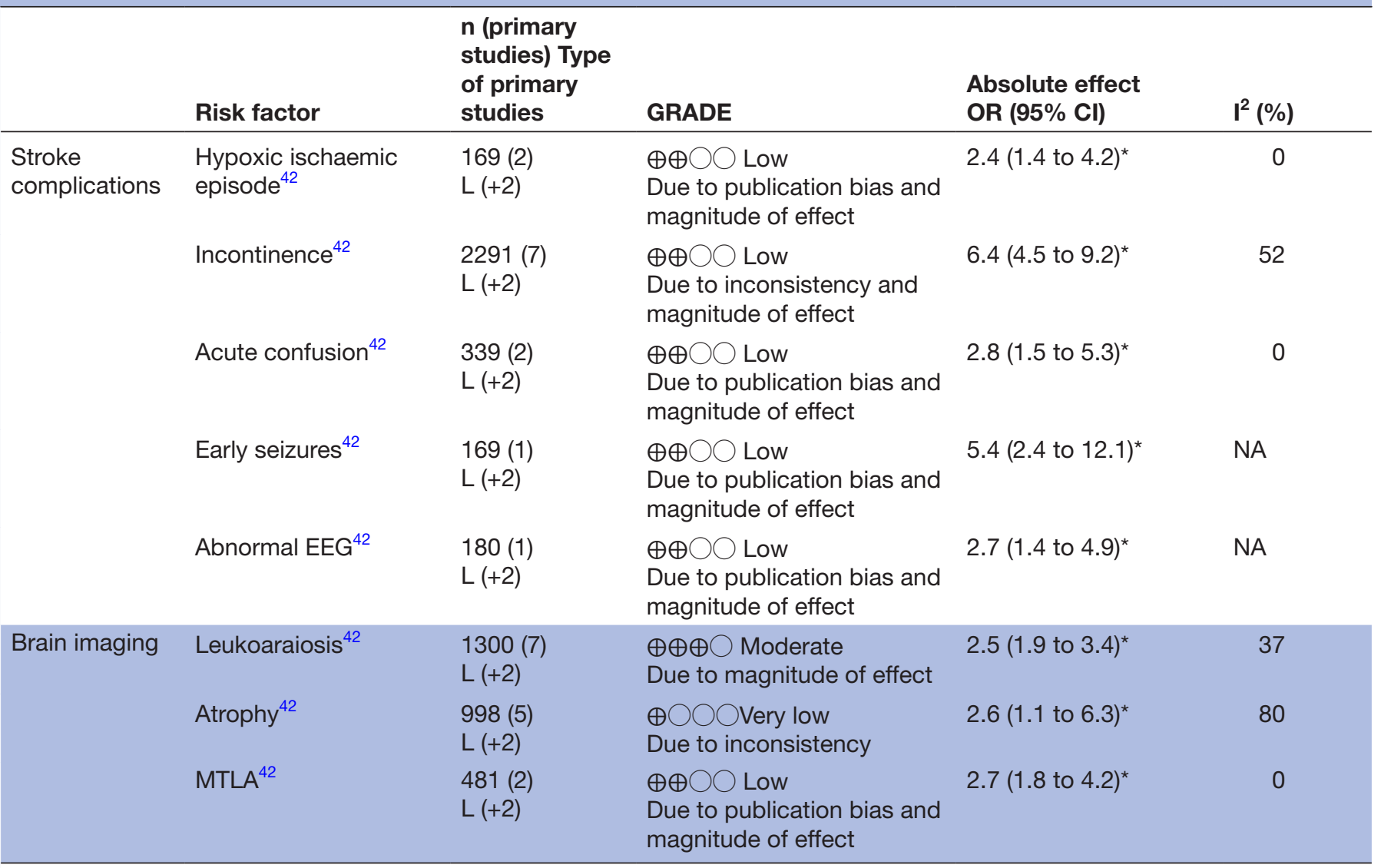

Our certainty level of each outcome is presented using GRADE. ${ }^{24}$

*Statistically significant.

†Relative risk.

$\ddagger$ Subset.

EEG, electroencephalogram; GRADE, Grading of Recommendations, Assessment, Development and Evaluations; L, longitudinal observational study; MTLA, medial temporal lobe atrophy; NA, not available; TIA, transient ischaemic attack.

\section{Quality assessment}

The quality assessment of the included SRs $(n=22)$ revealed 8 to be of high quality, ${ }^{9} 31 \quad 32 \quad 34 \quad 36 \quad 38-40 \quad 12$ of moderate quality, ${ }^{8} 10162627293033353741421$ of low quality $^{28}$ and 1 of critically low quality. ${ }^{11}$ We observed issues concerning investigating reporting bias, stating prior protocol, justification of excluded studies and reporting the sources of funding across many studies included. We also accounted for primary study quality reported in the SRs, which showed a moderate quality on average across primary studies. However, one SR included high-quality studies, ${ }^{8}$ moderate to low quality was observed in nine, ${ }^{9} 16283032-3539$ while low quality in two. ${ }^{36} 37$ Information on quality assessment for each SR included in the current study is presented in online supplementary file 2 .

\section{DISCUSSION}

Poststroke cognitive impairment has gained increased attention recently due to its high prevalence and implication on health. A James Lind Alliance priority setting exercise found that investigating ways to prevent poststroke cognitive impairment was the number one research priority for patients, carers and clinicians. ${ }^{7}$ There is a growing literature on the importance of poststroke cognitive impairment as a determinant of return to work for stroke survivors. ${ }^{3}$ In this umbrella review, we sought to understand the current state of the research into the risks for and treatment of cognitive impairment after stroke, and provide insights for healthcare workers, policymakers and researchers to help them gain a clear understanding of the existing options to prevent, preserve or improve cognitive decline. We judged strong evidence of associations with four risk factors and determinants, including: $\mathrm{AF},{ }^{104142}$ leukoaraiosis, multiple areas of stroke and recurrent strokes. ${ }^{42}$ This study also points to interventions that might warrant attention in the development of prevention/treatment strategies. Overall, physical activity ${ }^{26} 2730$ and cognitive rehabilitation interventions ${ }^{31}$ hold promise, which showed evidence of improving cognition performance after stroke. We also highlighted the key problems of previous reviews which in this topic are numerous, including methodological limitations, performance bias, barriers and biologically implausible interventions. 
Table 4 Summary of interventions using GRADE

\begin{tabular}{|c|c|c|c|c|c|c|c|}
\hline & \multicolumn{3}{|c|}{ Outcome characteristics and quality } & \multicolumn{4}{|c|}{ Anticipated absolute effect } \\
\hline & Intervention & $\begin{array}{l}\text { n (primary } \\
\text { studies) } \\
\text { Type of } \\
\text { primary } \\
\text { study }\end{array}$ & GRADE & $\begin{array}{l}\text { MD }(95 \% \mathrm{Cl}) / \\
\text { assessment time }\end{array}$ & $\begin{array}{l}\text { Cognitive } \\
\text { assessment } \\
\text { instrument (max } \\
\text { score) }\end{array}$ & $\begin{array}{l}\text { Cognition } \\
\text { improvement } \\
\text { in percentage }\end{array}$ & $I^{2} /$ follow-up time \\
\hline \multirow[t]{5}{*}{$\begin{array}{l}\text { Non- } \\
\text { pharmacological }\end{array}$} & Acupuncture $^{33}$ & $\begin{array}{l}1421(21) \\
\operatorname{RCT}(+4)\end{array}$ & $\begin{array}{l}\oplus \oplus \bigcirc \bigcirc \text { Low } \\
\text { Due to limitations } \\
\text { in quality and } \\
\text { publication bias }\end{array}$ & $\begin{array}{l}3.14(2.06 \text { to } \\
4.21)^{\star} \dagger \\
2.03(0.26 \text { to } \\
3.80)^{\star} \ddagger \\
5.6(3.95 \text { to } 7.31)^{\star}\end{array}$ & $\begin{array}{l}\text { MMSE (30) } \\
\text { MMSE (30) } \\
\text { NCSE (12) }\end{array}$ & $\begin{array}{l}10.4 \%(6.8-14) \\
6.7 \%(0.8-12) \\
46 \%(32-60)\end{array}$ & $\begin{array}{l}I^{2}=36 \% \\
I^{2}=72 \% \\
I^{2}=0 \% / 4-8 \text { weeks }\end{array}$ \\
\hline & Virtual reality $^{8}$ & $\begin{array}{l}97(4) \S \\
\operatorname{RCT}(+4)\end{array}$ & $\begin{array}{l}\oplus \oplus \bigcirc \bigcirc \text { Low } \\
\text { Due to } \\
\text { imprecision and } \\
\text { limitations in } \\
\text { quality }\end{array}$ & $\begin{array}{l}0.45(0.05 \text { to } \\
0.85)^{\star} \mathbb{9} \\
\text { End of intervention }\end{array}$ & NA & NA & $\begin{array}{l}\mathrm{I}^{2}=14.6 \% / \text { no follow- } \\
\text { up data }\end{array}$ \\
\hline & $\begin{array}{l}\text { Cognitive } \\
\text { rehabilitation; for } \\
\text { memory training }^{9}\end{array}$ & $\begin{array}{l}514(13) \dagger \\
\mathrm{RCT}(+4)\end{array}$ & $\begin{array}{l}\oplus \bigcirc \bigcirc \bigcirc \text { Very low } \\
\text { Due to limitations } \\
\text { in quality, } \\
\text { indirectness and } \\
\text { imprecision }\end{array}$ & $\begin{array}{l}0.25(-0.36 \text { to } \\
0.86) \text { १ } \\
0.21(-0.03 \text { to } \\
0.46) \text { ? } \\
\text { End of intervention }\end{array}$ & $\begin{array}{l}\text { RBMT, Wechsler } \\
\text { Memory Scale }\end{array}$ & NA & $\begin{array}{l}\mathrm{l}^{2}=42 \% \\
\mathrm{I}^{2}=0 \% / 6 \text { weeks to } 5 \\
\text { months }\end{array}$ \\
\hline & $\begin{array}{l}\text { Cognitive } \\
\text { rehabilitation for } \\
\text { attention deficits }^{32}\end{array}$ & $\begin{array}{l}223(6) \\
\operatorname{RCT}(+4)\end{array}$ & $\begin{array}{l}\oplus \oplus \bigcirc \bigcirc \text { Low } \\
\text { Due to } \\
\text { indirectness and } \\
\text { imprecision }\end{array}$ & $\begin{array}{l}0.67(0.35 \text { to } \\
0.98)^{\star} \emptyset \\
\text { End of intervention } \\
0.53(-0.03 \text { to } \\
1.08) \text { व } \\
\text { End of intervention } \\
-0.08 \text { ( }-0.35 \text { to } \\
0.18) \text { l } \\
\text { End of intervention }\end{array}$ & $\begin{array}{l}\text { Divided attention } \\
\text { (Paced Auditory } \\
\text { Serial Addition Test) } \\
\text { Global attention } \\
\text { (cognitive failures or } \\
\text { mental slowness) } \\
\text { Selective attention }\end{array}$ & NA & $1^{2}=N A / N A$ \\
\hline & $\begin{array}{l}\text { Chinese herbal } \\
\text { medicine } \\
\text { (mailuoning) }^{38}\end{array}$ & $\begin{array}{l}62(1) \S \\
\operatorname{RCT}(+4)\end{array}$ & $\begin{array}{l}\oplus \bigcirc \bigcirc \bigcirc \text { Very low } \\
\text { Due to limitations } \\
\text { in quality, } \\
\text { indirectness and } \\
\text { publication bias }\end{array}$ & $\begin{array}{l}2.68(1.82 \text { to } 3.54)^{\star} \\
\text { End of intervention }\end{array}$ & $\operatorname{MoCA}(30)$ & $9 \%(6-11)$ & $\mathrm{I}^{2}=\mathrm{NA} / 14$ days \\
\hline \multirow[t]{3}{*}{ Pharmacological } & $\begin{array}{l}\text { Antihypertension } \\
\text { medication } \\
\text { withdrawal for } 7 \\
\text { days }^{38}\end{array}$ & $\begin{array}{l}1784(1) \S \\
\mathrm{RCT}(+4)\end{array}$ & $\begin{array}{l}\oplus \bigcirc \bigcirc \bigcirc \text { Very low } \\
\text { Due to limitations } \\
\text { in quality, } \\
\text { indirectness and } \\
\text { imprecision }\end{array}$ & $\begin{array}{l}1(0.35 \text { to } 1.65)^{\star} \\
\text { At } 90 \text { days }\end{array}$ & MMSE (30) & $3 \%(1-5)$ & $\mathrm{I}^{2}=\mathrm{NA} / 16$ weeks \\
\hline & $\begin{array}{l}\text { Selective } \\
\text { serotonin } \\
\text { reuptake } \\
\text { inhibitor }^{39}\end{array}$ & $\begin{array}{l}425(7) \dagger \\
\mathrm{RCT}(+4)\end{array}$ & $\begin{array}{l}\oplus \bigcirc \bigcirc \bigcirc \text { Very low } \\
\text { Due to limitations } \\
\text { in quality, } \\
\text { inconsistency } \\
\text { and imprecision }\end{array}$ & $\begin{array}{l}0.32(-0.23 \text { to } \\
0.86) 9 \\
\text { End of intervention }\end{array}$ & NA & NA & $\mathrm{I}^{2}=86 \% / \mathrm{NA}$ \\
\hline & $\begin{array}{l}\text { Antidepressant } \\
\text { agents }^{34}\end{array}$ & $\begin{array}{l}82(1) \dagger \\
\operatorname{RCT}(+4)\end{array}$ & $\begin{array}{l}\oplus \oplus \bigcirc \bigcirc \text { Low } \\
\text { Due to } \\
\text { indirectness and } \\
\text { imprecision }\end{array}$ & $\begin{array}{l}-0.30 \text { ( }-3.27 \text { to } \\
2.67) \\
\text { End of intervention }\end{array}$ & MMSE (30) & $-1 \%(-10$ to 9$)$ & $\mathrm{I}^{2}=\mathrm{NA} / 6$ weeks \\
\hline
\end{tabular}

Continued 
Table 4 Continued

\begin{tabular}{|c|c|c|c|c|c|c|c|}
\hline & \multicolumn{3}{|c|}{ Outcome characteristics and quality } & \multicolumn{4}{|c|}{ Anticipated absolute effect } \\
\hline & Intervention & $\begin{array}{l}\text { n (primary } \\
\text { studies) } \\
\text { Type of } \\
\text { primary } \\
\text { study }\end{array}$ & GRADE & $\begin{array}{l}\text { MD }(95 \% \mathrm{Cl}) / \\
\text { assessment time }\end{array}$ & $\begin{array}{l}\text { Cognitive } \\
\text { assessment } \\
\text { instrument (max } \\
\text { score) }\end{array}$ & $\begin{array}{l}\text { Cognition } \\
\text { improvement } \\
\text { in percentage }\end{array}$ & $\mathrm{I}^{2} /$ follow-up time \\
\hline \multirow[t]{5}{*}{ Physical activity } & Active sessions ${ }^{26}$ & $\begin{array}{l}482(12) \\
\mathrm{RCT}(+4)\end{array}$ & $\begin{array}{l}\oplus \bigcirc \bigcirc \bigcirc \text { Very low } \\
\text { Due to limitations } \\
\text { in quality, } \\
\text { indirectness and } \\
\text { imprecision }\end{array}$ & $\begin{array}{l}0.2(0.04 \text { to } 0.36)^{*} \ddagger \\
\text { End of intervention } \\
\text { (varied) }\end{array}$ & $\begin{array}{l}\text { MMSE (30) } \\
\text { FIM } \\
\text { SIS }\end{array}$ & $1 \%(0.2-3)$ & $1^{2}=0 \% / 1-12$ months \\
\hline & $\begin{array}{l}\text { Aerobics and } \\
\text { stretching }\end{array}$ & $\begin{array}{l}736(14) \\
\text { RCT (+4) }\end{array}$ & $\begin{array}{l}\oplus \oplus \oplus \bigcirc \text { Moderate } \\
\text { Due to } \\
\text { imprecision and } \\
\text { study limitations }\end{array}$ & $\begin{array}{l}0.3(0.14 \text { to } 0.47)^{\star} \\
\text { Immediately after } \\
\text { intervention }\end{array}$ & $\begin{array}{l}\text { MMSE (30) } \\
\text { MoCA (30) } \\
\text { ACE-R }\end{array}$ & $2 \%(1-3)$ & $\mathrm{I}^{2}=15.3 \% / \mathrm{NA}$ \\
\hline & Aerobics $^{27}$ & $\begin{array}{l}394(10) \dagger \\
\text { RCT (+4) }\end{array}$ & $\begin{array}{l}\oplus \bigcirc \bigcirc \bigcirc \text { Very low } \\
\text { Due to limitations } \\
\text { in quality, } \\
\text { inconsistency } \\
\text { and imprecision }\end{array}$ & $\begin{array}{l}1.30(0.93 \text { to } 1.67)^{\star} \\
-0.25(-1.3 \text { to } 0.3) \\
0.79(0.08 \text { to } 1.50)^{\star} \\
5.14(1.16 \text { to } 9.12)^{\star} \\
\text { Varied time of } \\
\text { assessment }\end{array}$ & $\begin{array}{l}\text { MoCA (30) } \\
\text { MMSE (30) } \\
\text { P300 wave (20) } \\
\text { ACE-R (100) }\end{array}$ & $\begin{array}{l}4 \%(3-5) \\
0.8 \%(-4 \text { to } 1) \\
4 \%(0.4-7) \\
5 \%(1-9)\end{array}$ & $\begin{array}{l}I^{2}=N A \\
I^{2}=N A \\
I^{2}=0 \% \\
I^{2}=N A / N A\end{array}$ \\
\hline & Mixed activity ${ }^{36}$ & $\begin{array}{l}159(2) \S^{\star \star} \\
\operatorname{RCT}(+4)\end{array}$ & $\begin{array}{l}\oplus \oplus \bigcirc \bigcirc \text { Low } \\
\text { Due to limitations } \\
\text { in quality and } \\
\text { imprecision }\end{array}$ & $\begin{array}{l}-0.08 \text { ( }-0.47 \text { to } \\
0.31) \\
\text { End of intervention }\end{array}$ & FIM cognition (35) & $\begin{array}{l}-0.2 \%(-1 \\
\text { to } 1)\end{array}$ & $\mathrm{I}^{2}=18 \% / 4-6$ months \\
\hline & $\begin{array}{l}\text { Aerobics and } \\
\text { stretching }^{35}\end{array}$ & $\begin{array}{l}38(1) \S \\
\operatorname{RCT}(+4)\end{array}$ & $\begin{array}{l}\oplus \oplus \bigcirc \bigcirc \text { Low } \\
\text { Due to limitations } \\
\text { in quality and } \\
\text { imprecision }\end{array}$ & $\begin{array}{l}-0.83(-2.5 \text { to } \\
0.87) \\
0.20(-0.44 \text { to } \\
0.84) 9 \\
\text { End of intervention }\end{array}$ & $\begin{array}{l}\text { MMSE (30) } \\
\text { FIM total }\end{array}$ & $-3 \%(-8$ to 3$)$ & $\mathrm{I}^{2}=\mathrm{NA} / 8$ weeks \\
\hline
\end{tabular}

Our certainty level of each outcome is presented using GRADE. ${ }^{24}$

*Statistically significant.

†Short-term cognition (4 weeks)

ҒLong-term cognition (8 weeks).

§Subset.

IStandardised mean difference.

**One RCT excluded due to no follow-up data.

ACE-R, Addenbrooke's Cognitive Examination-Revised; FIM, functional independence measure; GRADE, Grading of Recommendations, Assessment,

Development and Evaluations; MD, mean difference; MMSE, Mini-Mental State Examination; MoCA, Montreal Cognitive Assessment; NA, not available; NCSE, The Neurobehavioral Cognitive Status Examination; RBMT, Rivermead Behavioural Memory Test; RCT, randomised controlled trial; SIS, six-item screener.;

This study confirms that in three SRs, ${ }^{10} 4142$ including 25 primary studies and 7466 participants, AF was strongly associated with increased risk of poststroke cognitive impairment, with estimates of the OR between 2.0 and 3.0. Such a large increase in cognitive impairment among stroke survivors with AF provides an additional motivation for prompt identification and treatment with anticoagulation. These findings might inform the current controversy surrounding surveillance and screening for $\mathrm{AF}^{43}$ Also, our findings may inform prescribing practices. Data from clinical practice observed that suboptimal oral anticoagulant is used in patients with $\mathrm{AF}$, especially with high stroke risks. ${ }^{44}$ The current data from this umbrella review may tip the balance further in favour of choosing anticoagulation even where there are relative contraindications such as risk of falls.

Other strongly associated risk factors we identified were related directly to stroke aetiology, including leukoaraiosis in brain imaging, multiple and recurrent strokes. ${ }^{42}$ Future research could determine whether more intensive screening and monitoring (to diagnose and support dementia earlier), or more intensive control of cardiovascular risk factors in this group might have benefit. Secondary preventive therapies, which are prescribed among a high-risk population to prevent cardiovascular events, might have an additional impact on cognitive function outcomes after stroke. An observational longitudinal study conducted by Douiri $e t a l^{45}$ investigated the association between secondary preventive treatments and long-term cognition function outcomes after stroke $(n=4413)$. The authors observed that appropriate pharmacological control of vascular risk factors after stroke has an impact on stroke recurrence prevention and long-term cognitive function outcomes.

Perhaps surprisingly, we found only low-quality and inconsistent evidence that cardiovascular risk factors were associated with poststroke cognitive impairment, leading to a 'low-certainty' GRADE rating. The main issues were related to non-significant estimates and methodological limitations. However, stroke survivors with diabetes, but not hypertension, were at higher risk of cognitive impairment at OR $1.4(1.2-1.7) .{ }^{42}$ We still lack good quality longitudinal studies with adjustment for confounders, 
such as stroke severity, baseline treatment and other poststroke disabilities.

The results from the RCTs of interventions were all rated as being of low certainty. Nonetheless, physical activity $^{262730}$ and cognitive rehabilitation ${ }^{9} 3132$ interventions were the most commonly tested interventions. From our GRADE assessment we believe the presented estimates were close to the actual effect. ${ }^{30} 31$ Key limitations we observed across studies we included were including patients who had a stroke and patients without a stroke, ${ }^{26}$ small effect size, ${ }^{26} 273031$ and including non-randomised trials. ${ }^{27}$ Physical activity interventions hold promise as providing an accessible and low-cost treatment that may preserve or restore poststroke cognitive function, which can be easily implemented in stroke services. However, there are barriers which should be highlighted to inform future researches. Many stroke survivors suffer from severe physical disability which may limit survivors' ability to participate in or derive benefit from physical activity rehabilitation programmes. ${ }^{46}$ The literature shows low participation rates in physical rehabilitation early after stroke. Factors associated with low attendance were older age, cardiac diseases, arthritis and cognitive impairment severity. ${ }^{48}$

Our findings suggested that cognitive rehabilitation interventions ${ }^{9132}$ seem to be effective to improve cognitive function after stroke. The most recently published SR observed medium effect of cognitive function improvement in a small magnitude $(g=0.48)$ beyond that experienced with natural recovery, ${ }^{31}$ while previous reviews failed to capture such effect. ${ }^{932}$ This is might be explained by methods used for cognitive assessment, both studies focused on a single cognitive domain. This finding is important for stroke survivors, who have pressing rehabilitation needs, but often exhibit reduced physical and mental stamina. ${ }^{49}$ Our findings support conclusion from previous longitudinal study that suggested cognitive rehabilitation might help to increase chance to return to work. ${ }^{50}$ However, further study is required.

We, additionally, could not be certain of the interventions that did not show positive effects, such as occupational therapy. ${ }^{16}$ These interventions are commonly used among cognitively impaired stroke survivors in stroke services. We therefore might need further good quality RCTs to observe the actual possible effects on poststroke cognitive function.

\section{Strength and limitation}

This umbrella review study provides insights for healthcare workers, policymakers and researchers to help them gain a clear understanding of the existing options to prevent, preserve or improve cognitive decline. ${ }^{51}$ To the best of our knowledge, this is the first umbrella review that synthesised the available options to prevent or improve this condition. The strength of this study is that it provides an overview on a broad topic by using a systematic approach to show what has been achieved and to suggest plans to understand what we need in future studies. Furthermore, as it included only SRs of RCTs to assess the effectiveness of an intervention, and longitudinal observational studies to evaluate the association of risk factors, it may provide reliable and valid results. In addition, the quality of the evidence was assessed at different levels, including GRADE criteria, which lends it more credibility. Although we rely on studies being included in primary SRs (any studies not in reviews would not have been captured), use of the umbrella methodology allows the research to be analysed on a much wider area than would be feasible with SRs of the primary research.

One of the limitations of our umbrella review is that we rely on the data extracted and bias assessments done by different reviewers and instruments. Additionally, this review did not account for non-longitudinal studies to evaluate risk factors and non-RCTs to understand interventions. Another, even though we used different level of quality assessments, conducting umbrella review might carry forward the methodological limitations of previous reviews. Next, although we tried to screen, identify and include all the studies that investigated poststroke cognitive impairment by using wide and validated search terms and different search methods, some relevant research could have been missed.

\section{Future study direction}

We observed poor methodological quality across the RCTs within this review, and therefore, we urgently need highquality research in this area. Key issues included poor methodological quality, imprecise estimates of treatment effects and risk of performance bias. Likewise, many of the studies of risk factors were limited by being retrospective and with inadequate adjustment for confounders.

\section{CONCLUSION}

Across a wide range of risk factors identified, this umbrella review confirms that $\mathrm{AF}$, leukoaraiosis, and recurrent and multiple strokes are associated with increased risk of poststroke cognitive impairment. These could provide a promising basis for future research into more intensive prevention, monitoring, risk factor treatment and other intervention in these groups. Furthermore, interventions that included physical activity and cognitive rehabilitation seem to enhance poststroke cognitive function. However, the low quality of the current trial evidence precludes any recommendations for changes in practice.

Contributors Conceived the study: M0, AD, IJM. Conducted the search and registered the protocol: MO. Searched abstracts: MO, AD, IJM. Assessed the quality: MO, AD, IJM, VP. Initiated a first draft: MO. Commented on drafts: MO, AD, IJM, CF, VP. Revised the final version: all authors.

Funding This is the first PhD study for M0, who is funded by Umm Al-Qura University, Makkah, Saudi Arabia. VP is funded by a National Institute for Health Research (NIHR) Academic Clinical Lecturer post in General Practice, hosted by King's College London.

Competing interests None declared. 
Patient and public involvement Patients and/or the public were not involved in the design, or conduct, or reporting, or dissemination plans of this research.

Patient consent for publication Not required.

Provenance and peer review Not commissioned; externally peer reviewed.

Data availability statement № data are available. No additional data available.

Open access This is an open access article distributed in accordance with the Creative Commons Attribution Non Commercial (CC BY-NC 4.0) license, which permits others to distribute, remix, adapt, build upon this work non-commercially, and license their derivative works on different terms, provided the original work is properly cited, appropriate credit is given, any changes made indicated, and the use is non-commercial. See: http://creativecommons.org/licenses/by-nc/4.0/.

\section{ORCID iDs}

Majed Obaid http://orcid.org/0000-0003-0719-5632

lain Marshall http://orcid.org/0000-0003-2594-2654

\section{REFERENCES}

1 Feigin VL, Forouzanfar MH, Krishnamurthi R, et al. Global and regional burden of stroke during 1990-2010: findings from the global burden of disease study 2010. The Lancet 2014;383:245-55.

2 Langa KM, Chernew ME, Kabeto MU, et al. National estimates of the quantity and cost of informal caregiving for the elderly with dementia $J$ Gen Intern Med 2001;16:770-8.

3 Edwards JD, Kapoor A, Linkewich E, et al. Return to work after young stroke: a systematic review. Int J Stroke 2018;13:243-56.

4 Obaid M, Flach C, Marshall I, et al. Long-Term outcomes in stroke patients with cognitive impairment: a population-based study. Geriatrics 2020:5:32.

5 Claesson L, Lindén T, Skoog I, et al. Cognitive impairment after stroke - impact on activities of daily living and costs of care for elderly people. Cerebrovasc Dis 2005;19:102-9.

6 Ankolekar S, Geeganage C, Anderton P, et al. Clinical trials for preventing post stroke cognitive impairment. J Neurol Sci 2010;299:168-74.

7 Pollock A, St George B, Fenton M, et al. Top 10 research priorities relating to life after stroke--consensus from stroke survivors, caregivers, and health professionals. Int J Stroke 2014;9:313-20.

8 Aminov A, Rogers JM, Middleton S, et al. What do randomized controlled trials say about virtual rehabilitation in stroke? A systematic literature review and meta-analysis of upper-limb and cognitive outcomes. J Neuroeng Rehabil 2018;15:29.

9 das Nair R, Cogger H, Worthington E, et al. Cognitive rehabilitation for memory deficits after stroke. Cochrane Database Syst Rev 2016;26.

10 Kalantarian S, Stern TA, Mansour M, et al. Cognitive impairment associated with atrial fibrillation: a meta-analysis. Ann Intern Med 2013:158:338-46.

11 Tang EY, Amiesimaka O, Harrison SL, et al. Longitudinal effect of stroke on cognition: a systematic review. J Am Heart Assoc 2018;7:e006443.

12 Smith V, Devane D, Begley CM, et al. Methodology in conducting a systematic review of systematic reviews of healthcare interventions. BMC Med Res Methodol 2011;11:15.

13 Liberati Aet al. The PRISMA statement for reporting systematic reviews and meta-analyses of studies that evaluate health care interventions: explanation and elaboration. Ann Intern Med 2009;151:W-65-W-94.

14 loannidis JPA. Integration of evidence from multiple meta-analyses: a primer on umbrella reviews, treatment networks and multiple treatments meta-analyses. CMAJ 2009;181:488-93.

15 OpenGray. Gray literature in Europe. Available: http://www.opengrey. eu

16 Hoffmann T, Bennett S, Koh C, et al. The Cochrane review of occupational therapy for cognitive impairment in stroke patients. [Reprint of Cochrane Database Syst Rev. 2010;(9):CD006430; PMID: 20824849]. European journal of physical \& rehabilitation medicine 2011;47:513-9.

17 Hatano S. Experience from a multicentre stroke register: a preliminary report. Bull World Health Organ 1976;54:541.

18 Hoffmann T, Bennett S, Koh C-L, et al. A systematic review of cognitive interventions to improve functional ability in people who have cognitive impairment following stroke. Top Stroke Rehabil 2010;17:99-107.

19 Gorelick PB, Scuteri A, Black SE, et al. Vascular contributions to cognitive impairment and dementia: a statement for healthcare professionals from the American heart association/american stroke association. Stroke 2011;42:2672-713.

20 Cicerone KD, Dahlberg C, Malec JF, et al. Evidence-Based cognitive rehabilitation: updated review of the literature from 1998 through 2002. Arch Phys Med Rehabil 2005;86:1681-92.

21 Hill K. Australian clinical guidelines for acute stroke management 2007: acute stroke guidelines writing subgroup on behalf of the National stroke Foundation clinical guidelines for acute stroke management expert Working group. International Journal of Stroke 2008;3:120-9.

22 Higgins JPT, Thompson SG, Deeks JJ, et al. Measuring inconsistency in meta-analyses. BMJ 2003;327:557-60.

23 Feeney J, Savva GM, O'Regan C, et al. Measurement error, reliability, and minimum detectable change in the Mini-Mental state examination, Montreal cognitive assessment, and color trails test among community living middle-aged and older adults. J Alzheimers Dis 2016:53:1107-14.

24 Guyatt GH, Oxman AD, Schünemann HJ, et al. GRADE guidelines: a new series of articles in the Journal of clinical epidemiology. J Clin Epidemiol 2011;64:380-2.

25 Shea BJ, Reeves BC, Wells G, et al. AMSTAR 2: a critical appraisal tool for systematic reviews that include randomised or nonrandomised studies of healthcare interventions, or both. BMJ 2017;358:j4008.

26 Cumming TB, Tyedin K, Churilov L, et al. The effect of physical activity on cognitive function after stroke: a systematic review. Int Psychogeriatr 2012;24:557-67.

27 Zheng G, Zhou W, Xia R, et al. Aerobic exercises for cognition rehabilitation following stroke: a systematic review. J Stroke Cerebrovasc Dis 2016;25:2780-9.

28 Sami MB, Faruqui R. The effectiveness of dopamine agonists for treatment of neuropsychiatric symptoms post brain injury and stroke. Acta Neuropsychiatr 2015;27:317-26.

29 Braun S, Kleynen M, van Heel T, et al. The effects of mental practice in neurological rehabilitation; a systematic review and meta-analysis. Front Hum Neurosci 2013;7.

30 Oberlin LE, Waiwood AM, Cumming TB, et al. Effects of physical activity on poststroke cognitive function: a meta-analysis of randomized controlled trials. Stroke 2017;48:3093-100.

31 Rogers JM, Foord R, Stolwyk RJ, et al. General and domainspecific effectiveness of cognitive remediation after stroke: systematic literature review and meta-analysis. Neuropsychol Rev 2018;28:285-309.

32 Loetscher T, Lincoln NB, Cochrane Stroke Group. Cognitive rehabilitation for attention deficits following stroke. Cochrane Database Syst Rev 2013;40:CD002842.

33 Liu F, Li Z-M, Jiang Y-J, et al. A meta-analysis of acupuncture use in the treatment of cognitive impairment after stroke. $J$ Altern Complement Med 2014;20:535-44.

34 Hackett ML, Yang M, Anderson CS, et al. Pharmaceutical interventions for emotionalism after stroke. Cochrane Database Syst Rev 2010:CD003690.

35 Pang MYC, Charlesworth SA, Lau RWK, et al. Using aerobic exercise to improve health outcomes and quality of life in stroke: evidencebased exercise prescription recommendations. Cerebrovasc Dis 2013;35:7-22.

36 Hayes S, Saunders D, Greig C, et al. Physical fitness training and cognitive function for stroke patients (review). Cerebrovascular Diseases 2016;1:117.

37 Tian $\mathrm{Y}$, Kang L, Wang $\mathrm{H}$, et al. Meta-Analysis of transcranial magnetic stimulation to treat post-stroke dysfunction. Neural Regeneration Research 2011:6:1736-41.

38 Jongstra S, Harrison JK, Quinn TJ, et al. Antihypertensive withdrawal for the prevention of cognitive decline. Cochrane Database Syst Rev 2016;11:CD011971.

39 Mead GE, Hsieh C-F, Lee R, et al. Selective serotonin reuptake inhibitors (SSRIs) for stroke recovery. Cochrane Database Syst Rev 2012;11:CD009286.

40 Yang W, Shi Z, Yang H-Q, et al. Mailuoning for acute ischaemic stroke. Cochrane Database Syst Rev 2015;1:CD007028.

41 Kwok CS, Loke YK, Hale R, et al. Atrial fibrillation and incidence of dementia: a systematic review and meta-analysis. Neurology 2011;76:914-22

42 Pendlebury ST, Rothwell PM. Prevalence, incidence, and factors associated with pre-stroke and post-stroke dementia: a systematic review and meta-analysis. Lancet Neurol 2009;8:1006-18.

43 Curry SJ, Krist AH, et al, US Preventive Services Task Force. Screening for atrial fibrillation with electrocardiography: US preventive services Task force recommendation statement. JAMA 2018;320:478-84. 
44 Alamneh EA, Chalmers L, Bereznicki LR. Suboptimal use of oral anticoagulants in atrial fibrillation: has the introduction of direct oral anticoagulants improved prescribing practices? Am J Cardiovasc Drugs 2016;16:183-200.

45 Douiri A, McKevitt C, Emmett ES, et al. Long-Term effects of secondary prevention on cognitive function in stroke patients. Circulation 2013;128:1341-8.

46 Plummer P, Eskes G, Wallace S, et al. Cognitive-Motor interference during functional mobility after stroke: state of the science and implications for future research. Arch Phys Med Rehabil 2013;94:2565-74.

47 Sagnier S, Renou P, Olindo S, et al. Gait change is associated with cognitive outcome after an acute ischemic stroke. Front Aging Neurosci 2017;9:153.

48 Prout EC, Brooks D, Mansfield A, et al. Patient characteristics that influence enrollment and attendance in aerobic exercise early after stroke. Arch Phys Med Rehabil 2015;96:823-30.
49 Acciarresi M, Bogousslavsky J, Paciaroni M. Post-Stroke fatigue: epidemiology, clinical characteristics and treatment. Eur Neurol 2014;72:255-61.

50 van der Kemp J, Kruithof WJ, Nijboer TCW, et al. Return to work after mild-to-moderate stroke: work satisfaction and predictive factors. Neuropsychol Rehabil 2019;29:638-53.

51 Aromataris E, Fernandez R, Godfrey CM, et al. Summarizing systematic reviews: methodological development, conduct and reporting of an umbrella review approach. Int J Evid Based Healtho 2015;13:132-40.

52 Delbari A, Salman-Roghani R, Lokk J. Effect of methylphenidate and/ or levodopa combined with physiotherapy on mood and cognition after stroke: a randomized, double-blind, placebo-controlled trial. Eur Neurol 2011;66:7-13.

53 Gorgoraptis N, Mah Y-H, Machner B, et al. The effects of the dopamine agonist rotigotine on hemispatial neglect following stroke. Brain 2012;135:2478-91. 